\title{
Indirect estimation of the prevalence of spinal muscular atrophy Type I, II, and III in the United States
}

\author{
Cathy Lally ${ }^{1 *}$, Cynthia Jones ${ }^{2}$, Wildon Farwell ${ }^{2}$, Sandra P. Reyna ${ }^{2}$, Suzanne F. Cook ${ }^{3}$ and W. Dana Flanders ${ }^{1}$
}

\begin{abstract}
Background: Spinal muscular atrophy (SMA) is a progressive, devastating disease and a leading inherited cause of infant mortality. The limited population-based literature is confined to small regional studies. Estimates of prevalence are needed to characterize the burden of SMA and to understand trends in prevalence by disease type as new treatments become available. The reported estimates of SMA genotype prevalence at birth consistently range from 8.5-10.3 per 100,000 live births, with a mid-range estimate of 9.4 per 100,000. Among infants born with an SMA genotype, it is reported that 58\% will develop SMA Type I, 29\% will develop Type II, and 13\% will develop Type III, respectively.
\end{abstract}

Results: Using evidence from peer-reviewed literature for SMA birth prevalence, age at symptom onset, and SMA type-specific survival, and incorporating United States vital statistics, we constructed life tables to estimate prevalence for SMA Types I, II, and III in the United States. We estimated the number of prevalent cases in the US to be 8526, 9429, and 10,333 based on a birth prevalence of 8.5, 9.4, and 10.3, respectively (the lower, midpoint, and upper ends of the reported range). Assuming the midpoint of 9.4 and US-reported survival, the type-specific population prevalence estimates were 1610 for SMA Type I, 3944 for SMA Type II, and 3875 for SMA Type III. Evidence-based estimates of the number of people living with SMA in the United States in the published literature were previously unavailable.

Conclusions: In the absence of a survey or other means to directly estimate prevalence in the US population, estimates can be calculated indirectly using a life table.

Keywords: Prevalence, Spinal muscular atrophy, Survival

\section{Background}

Spinal muscular atrophy (SMA) is an inherited autosomal recessive neuromuscular disorder characterized by degeneration of motor neurons in the spinal cord and lower brain stem, resulting in severe and progressive muscular atrophy and weakness [1,2]. SMA is caused by deletions or mutations in the survival motor neuron 1 (SMN1) gene, resulting in little to no function in the SMN protein, which is critical for the maintenance of motor neurons [3, 4]. In the absence of a functional SMN1 gene, the body relies on its homolog gene called SMN2 to produce SMN protein. The severity of SMA is

\footnotetext{
* Correspondence: clally@emory.edu

${ }^{1}$ Rollins School of Public Health, Emory University, Atlanta, GA, USA

Full list of author information is available at the end of the article
}

associated with the number of SMN2 gene copies present $[5,6]$. Clinically, SMA symptoms range from early infant death in children with SMA Type I to mild weakness in adults with SMA Type IV [7]. Specifically, children with SMA Type I, the most severe lifethreatening form, produce very little SMN protein and do not achieve the ability to sit without support or typically live beyond 2 years of age without respiratory support [8]. Individuals with SMA Types II and III produce greater amounts of SMN protein and have less severe but still clinically significant forms of SMA.

SMA is a progressive and devastating disease $[1,6,8-$ $10]$ and the leading cause of infant mortality from a single gene disorder $[6,11]$. With advances in understanding of the genetic basis of SMA, potential drug strategies include replacement or correction of the mutated SMN1 gene, 
modulation of the low-functioning SMN2 "back-up gene" that is unique to humans, neuroprotection of the motor neurons affected by loss of SMN protein, and muscle protection to prevent or restore loss of muscle function in SMA [6, 12]. The US Food and Drug Administration approved the first treatment for SMA in December 2016 [13]. As new treatments continue to be developed, there is an increased need for robust epidemiologic data to aid in the understanding of disease trends, inform policy regarding allocation of health care resources, anticipate future health care service needs, and support SMA advocacy efforts.

Specifically, as new treatments continue to become available, prevalence estimates are needed to characterize the changing burden of SMA and to understand trends in prevalence by type of SMA. Means of directly estimating the population prevalence include door-to-door surveys, analysis of hospital and clinic records, and systematic surveillance methods. Currently, there are no known mandatory surveillance systems (eg, newborn screening); thus, case reporting to inform the understanding of the size of the SMA population is likely to be incomplete. Studies have provided direct estimates, but only for small populations. Direct estimates of SMA for large populations would require significant resources.

Indirect estimation of SMA prevalence can be informative and cost effective by using available published data [14]. This approach can characterize prevalence of carrier status at birth, but does not directly estimate SMA prevalence in the population as a whole. Despite the limitations of estimates based on SMA carrier status, they can be used to estimate SMA birth prevalence. SMA population prevalence can then be indirectly estimated using SMA birth prevalence and SMA type-specific survival estimates. Available estimates of SMA birth prevalence have limitations. Some suggest that these reported estimates tend to be lower than those expected based on a projection from carrier status [15]. Recent studies of directly observed incidence (eg, incidence of diagnosed disease) that can be used to estimate prevalence indirectly tend to be regionally limited $[16,17]$ and report different carrier frequencies by geography $[15,18,19]$. Most published studies concerning prevalence and incidence do not provide estimates of survival. Geographical variation in treatment patterns and outcomes is not systematically documented and therefore precludes characterization of expected survival within the population [20-23]. Recognized phenotypes have different characteristics, including symptom onset that ranges from shortly after birth to months or years later [24, 25], as well as very different survival times. This heterogeneity adds to the complexity of prevalence estimation.

The objective of the current study was to estimate the prevalence of people who have been diagnosed and are living with SMA Types I, II, and III in the United States. We used an indirect approach, combining (1) evidence from peer-reviewed literature that provide estimates of the prevalence of an SMA genotype at birth, (2) age at symptom onset, and (3) survival. These estimates were incorporated with US vital statistics and used to construct life tables that provides prevalence estimates for SMA in the United States.

\section{Methods}

Indirect estimation using a life table method was employed to estimate the age- and type-specific prevalence of SMA. The goal was to estimate the total number of people living with symptomatic SMA Types I, II, and III in the United States. Current US age-specific population projections for the year 2016 were obtained from the Centers for Disease Control and Prevention [26]. Projected age-specific survival probabilities for the United States were obtained from the 2010 US life tables published in the Centers for Disease Control and Prevention's National Vital Statistics Report [27]. Prevalence estimates were calculated separately by SMA type to account for the differing rate of birth prevalence and estimated survival for each type. This method relied on the following 5 types of information. (1) Birth prevalence: here, "birth prevalence" is the proportion of newborns with an SMA genotype. We assumed that each baby born alive with an SMA genotype would eventually be recognized as having an SMA phenotype. We used a reported range of $8.5-10.3[16,19,28,29]$ per 100,000 live births, with 9.4 as a midpoint assessment of birth prevalence for SMA Types I, II, and III based on studies that reported population-based estimates of birth prevalence using contemporary case definitions and genetic confirmation, as well as clearly reported numerator and denominator for analysis. We assigned type-specific birth prevalence based on the distribution of SMA types in the published literature $[16,19,28,29]$. The typespecific distribution estimates used were $58 \%, 29 \%$, and 13\% for SMA Types I, II, and III, respectively [24]. (2) Disease onset: the estimated age of reported symptom onset and diagnosis (as a proxy for disease onset) from the literature for SMA Types I and II was $<1$ year. For SMA Type III, the earliest age at onset was in the second year, implying cases were not observed at birth or 1 year of age and thus no onset during this interval. [30] (3) SMA survival from birth: for SMA Types I and II, we used available survival estimates from the literature for studies in which survival was reported. We note that a limited body of literature was available and reflected large variation in standards of care and survival. [25] If $>1$ published estimate was available for a given age, a weighted average of published survival probabilities was used. For these types of SMA, the survival probability 
for the years not directly observed was interpolated based on periods with available probabilities, by assuming that the 1-year survival probability was constant. For SMA Types I and II, survival estimates were not reported in the literature beyond 20 and 40 years of age, respectively. For ages where survival estimates were unavailable in the literature, it was taken to be nearly 0 $\left(1 \times 10^{-6}\right)$ at and after the ages where available clinical evidence suggested an absence of living cases: 25 years for SMA Type I and 50 years for SMA Type II. For SMA Type III, survival was assumed to be that of the US population. (4) Age-specific survival estimates for the US population by 1-year age groups were taken from the most recent available life table estimates published in the National Vital Statistics Report [27]. (5) Number of persons in the population by age: age-specific (1-year age group) national population projections for the year 2016 were taken from the Centers for Disease Control and Prevention [26]. These population estimates were used to estimate the number of persons with SMA at each year of age.

Additional files 1, 2, 3, and 4 provide details of our calculations, such as the probability of having the diagnosis given survival through a specific age. This probability was multiplied by the US population at each given age to estimate number of people living with each type of SMA for each 1-year age group. The estimated number of prevalent cases of each SMA type was calculated using the sum of the number living with SMA for 0-100+ years of age.

\section{Results}

\section{Birth prevalence}

The estimates of SMA genotype prevalence at birth reported in the literature are consistently in a range from $8.5-10.3$ per 100,000 live births $[16,28]$ or $\sim 1$ per 10,000 live births globally (Additional file 1: Table S1). Among infants born with an SMA genotype, it is reported that $\sim 58 \%$ will develop SMA Type I, 29\% will develop SMA Type II, and 13\% will develop SMA Type III [24]. SMA Types 0 and IV are rarely observed [24].

\section{Survival estimates}

For SMA Type I, we reviewed 4 papers from the United States that provide survival estimates for patients with SMA Type I (Additional file 2: Table S2) [9, 31-33]. Survival probabilities across the 4 studies ranged from 37 $94 \%$ at 1 year and $31-87 \%$ at 2 years. Some studies reported survival probabilities at the following other time points: $26-72 \%$ [34] at 4 years and $8-50 \%$ at 10 years [35-37]. One study utilizing family-reported data found an $18 \%$ survival probability at 20 years of age [32]. The populations studied differed substantially in the use of respiratory support. Lemoine et al. (2012) found longer survival among patients for whom caregivers chose to provide noninvasive ventilation at night and daytime sleep and cough assist at least twice a day compared with patients without this support [31]. Oskoui et al. (2007) compared an earlier cohort of patients (19801994), an era before respiratory support became the standard of care, to a later cohort (1995-2006); significantly lower survival was observed in the earlier cohort than in the later cohort, a finding confirmed in later studies [32]. It is unknown how many patients with SMA in the United States receive respiratory support. Neither Finkel et al. nor Mannaa et al. reported survival according to use (actual or expected) of respiratory support $[9,33]$. Variation across studies also can be attributed to differences in data sources and capture; study periods before, during, or after more frequent use of respiratory support; study duration; and sample size.

Only 1 study reported survival estimate for SMA Type II in the United States. Mannaa et al. (2009) reported US survival for SMA Types I, II, and III (Additional file 3: Table S3) [33]. The survival of patients with SMA Type II was $100 \%$ at 1,2 , and 4 years of age. Beyond 4 years of age, the survival was $82 \%$ at 10 years and was unchanged at 15 years of age when the study terminated. Because we found only 1 study in the United States detailing survival for SMA Type II, we examined relevant studies in other countries [33, 35, 37] and found similar estimates to Mannaa et al. [33]. Details can be found in Additional files 1, 2, and 3 .

For SMA Type III, the literature reports a normal life expectancy (Additional file 3: Table S3) [33-37].

To evaluate the sensitivity of the estimated prevalence to the different survival rates reported in the literature and differing survival rates reported for patients treated versus untreated, we used 2 main values for survival: pooled estimates based on US populations only and pooled estimates based on US, European, and Australian populations. Reported survival estimates are lower in Europe, where respiratory support was less often noted, and result in lower prevalence estimates.

\section{Prevalent cases in the US}

Because we found a range of birth prevalence estimates in the literature, we estimated the 2016 US population prevalence of SMA Types I, II, and III using 3 birth prevalence estimates: either lower birth prevalence (8.5), higher birth prevalence (10.3), or the midpoint of the reported birth prevalence (9.4, an average of the 8.5-10.3 range of prevalence). We estimated the number of prevalent cases in the US to be 8526,9429 , and 10,333, based on a reported birth prevalence of 8.5, 9.4, and 10.3, respectively, and US-reported survival estimates (Tables 1, 2, and 3). Assuming the midpoint of 9.4 and US-reported survival, the type-specific numbers of prevalent cases were 1610 for SMA Type I, 3944 for 
Table 1 Estimated 2016 US SMA prevalence by type assuming a birth prevalence of 8.5 per 100,000

\begin{tabular}{lll}
\hline SMA type & Estimated prevalence $^{\text {a }}$ & Estimated prevalence $^{\text {b }}$ \\
\hline I & 1455 & 1067 \\
II & 3567 & 3330 \\
III & 3504 & 3504 \\
All & 8526 & 7901 \\
\hline
\end{tabular}

SMA spinal muscular atrophy

${ }^{a}$ Used published survival estimates from US literature only

bused combined published survival estimates from the United States, Europe, and Australia

SMA Type II, and 3875 for SMA Type III (Table 2). Type-specific estimates assuming the lowest- and highest-reported birth prevalence and estimates assuming a lower reported survival are reported in Tables 1, 2, and 3. The overall range of the number of people living with SMA Types I, II, and III in the United States based on reported birth prevalence and variability in reported survival estimates was 7901-10,333.

\section{Discussion}

Utilizing survival estimates from published US studies, we estimated that 8526-10,333 individuals with SMA Types I, II, and III are living in the United States in 2016. Approximately 1455-1764 of these people have SMA Type I, 35674322 have SMA Type II, and 3504-4247 have SMA Type III. Three estimates were calculated based on the highestand lowest-reported birth prevalence and 1 was based on an average of the 2 estimates. It should be noted that the average of 9.4 per 100,000 live births is closest to the estimates generated from US birth prevalence (Prior 2010 and Sugarman 2012), yielding an estimate of 9429 cases [19, 29]. Estimates calculated using survival probabilities reported from the United States generally suggest a higher prevalence than those estimates calculated using survival probabilities reported from Europe and Australia. Using combined survival probabilities from the United States, Europe, and Australia, we estimated that 7501-9575 individuals with SMA are living in the United States in 2016.

The distribution of prevalent cases we report, with more people having SMA Types II and III and fewer

Table 2 Estimated 2016 US prevalence of SMA by type assuming a birth prevalence of 9.4 per 100,000

\begin{tabular}{lll}
\hline SMA type & Estimated prevalence $^{a}$ & Estimated prevalence $^{b}$ \\
\hline I & 1610 & 1180 \\
II & 3944 & 3682 \\
III & 3875 & 3875 \\
All & 9429 & 8737
\end{tabular}

SMA spinal muscular atrophy

a Used published survival estimates from US literature only

bUsed combined published survival estimates from the United States, Europe, and Australia
Table 3 Estimated 2016 US prevalence of SMA by type assuming a birth prevalence of 10.3 per 100,000

\begin{tabular}{lll}
\hline SMA type & Estimated prevalence $^{a}$ & Estimated prevalence $^{b}$ \\
\hline I & 1764 & 1293 \\
III & 4322 & 4035 \\
All & 4247 & 4247 \\
\hline
\end{tabular}

SMA spinal muscular atrophy

a Used published survival estimates from US literature only

bUsed combined published survival estimates from the United States, Europe, and Australia

having SMA Type I, is expected because of the high case fatality among patients with SMA Type I. With advances in treatment and greater use of the recommended standard of care, prevalence, especially among patients with SMA Type I, is expected to increase over time.

The prevalence estimates are based on the US population estimates and US lifetables for survival. Therefore, the estimates cannot be extrapolated to other countries. However, the methods used to calculate the estimates can be applied to country-specific population estimates and lifetable estimates to derive estimates of the prevalence of SMA in other countries. It may be necessary to use different SMA survival estimates in countries where the treatment for SMA differs from that in the US.

\section{Limitations}

To approximate the number of patients at older ages, survival was assumed to be negligible after 25 years in patients with SMA Type I and 50 years in patients with SMA Type II. Second, survival expected for each year of life among those with SMA have not been reported. To estimate survival, we assumed a constant decline in survival between reporting periods (eg, constant decline in survival between 2 and 4,4 and 10, 10 and 20 years of age). Third, the standard of care demonstrates great variability so that survival in different periods is probably not constant. To the extent survival will likely increase in the future, the numbers of people living with SMA will tend to increase. Selection bias may be of concern in the published studies. If patients and their families who receive more aggressive care were more likely to participate, overestimation of survival could have resulted. Similar considerations hold for clinicians if those providing more aggressive care were more likely to conduct or participate in such studies.

\section{Conclusions}

Estimates of the number of people living with SMA in the United States in the published literature were previously unavailable. In the absence of a survey or other 
means to directly estimate prevalence in the US population, we used an indirect method. By utilizing available published estimates of genotype prevalence at birth, age of disease onset, and subsequent survival, we were able to estimate the SMA population for each year of age and subsequently for the entire population.

\section{Additional files}

Additional file 1: Table S1. Summary of contemporary published estimates of SMA birth prevalence. Table showing summary of contemporary published estimates of SMA birth prevalence. (DOCX $23 \mathrm{~kb}$ )

Additional file 2: Table S2. Summary of survival probabilities for patients with SMA Type I in the United States. Table showing summary of survival probabilities for patients with SMA Type I in the United States. (DOCX $20 \mathrm{~kb}$ )

Additional file 3: Table S3. Summary of survival probabilities for patients with SMA Type II in the United States. Table showing summary of survival probabilities for patients with SMA Type II in the United States. (DOCX $14 \mathrm{~kb}$ )

Additional file 4: Table S4. Methods. Table showing methods. (DOCX $16 \mathrm{~kb}$ )

\section{Abbreviations}

SMA: spinal muscular atrophy; SMN: survival motor neuron

\section{Acknowledgments}

Biogen provided funding for medical writing support in the development of this paper; Karen Spach from Excel Scientific Solutions wrote the first draft of the manuscript based on input from authors, and Kristen DeYoung from Excel Scientific Solutions copyedited and styled the manuscript per journal requirements. Biogen reviewed and provided feedback on the paper to the authors. The authors had full editorial control of the paper and provided their final approval of all content.

\section{Funding}

This study was sponsored by Biogen (Cambridge, MA, USA).

\section{Availability of data and materials}

Findings from this manuscript can be replicated via the data contained in the publications and websites referenced in the main body and appendices, including https://wonder.cdc.gov/wonder/help/PopulationProjections2060.html

\section{Authors' contributions}

All authors contributed to the study design, interpretation of the results, and development of the manuscript. CL, CJ, SFC, and WDF participated in the analysis. All authors read and approved the final manuscript.

\section{Ethics approval and consent to participate}

Not applicable.

\section{Consent for publication}

Not applicable.

\section{Competing interests}

CL, SFC, and WDF are consultants to Biogen. CJ, WF, and SPR are employees of and hold stock/stock options in Biogen.

\section{Publisher's Note}

Springer Nature remains neutral with regard to jurisdictional claims in published maps and institutional affiliations.

\section{Author details}

${ }^{1}$ Rollins School of Public Health, Emory University, Atlanta, GA, USA. ${ }^{2}$ Biogen, Cambridge, MA, USA. ${ }^{3}$ Epidemiology Associates LLC, Chapel Hill, NC, USA.
Received: 11 August 2017 Accepted: 15 November 2017

Published online: 28 November 2017

\section{References}

1. Lunn MR, Wang CH. Spinal muscular atrophy. Lancet. 2008;371(9630):2120-33.

2. Spinal muscular atrophy. GeneReviews ${ }^{\oplus}$. http://www.ncbi.nlm.nih.gov/ books/NBK1352/. Accessed 24 Aug 2017.

3. Lorson CL, Hahnen E, Androphy EJ, Wirth B. A single nucleotide in the SMN gene regulates splicing and is responsible for spinal muscular atrophy. Proc Natl Acad Sci U S A. 1999;96(11):6307-11.

4. Lefebvre S, Burglen L, Reboullet $\mathrm{S}$, Clermont O, Burlet P, Viollet L, Benichou $B$, Cruaud C, Millasseau P, Zeviani M, et al. Identification and characterization of a spinal muscular atrophy-determining gene. Cell. 1995;80(1):155-65.

5. Feldkötter M, Schwarzer V, Wirth R, Wienker TF, Wirth B. Quantitative analyses of SMN1 and SMN2 based on real-time LightCycler PCR: fast and highly reliable carrier testing and prediction of severity of spinal muscular atrophy. Am J Hum Genet. 2002;70(2):358-68.

6. Kolb SJ, Kissel JT. Spinal muscular atrophy. Neurol Clin. 2015;33(4):831-46.

7. Wang $\mathrm{CH}$, Finkel RS, Bertini ES, Schroth M, Simonds A, Wong B, Aloysius A, Morrison L, Main M, Crawford TO, et al. Consensus statement for standard of care in spinal muscular atrophy. J Child Neurol. 2007;22(8):1027-49.

8. Darras BT. Spinal muscular atrophies. Pediatr Clin North Am. 2015;62(3):743-66.

9. Finkel RS, McDermott MP, Kaufmann P, Darras BT, Chung WK, Sproule DM, Kang PB, Foley AR, Yang ML, Martens WB, et al. Observational study of spinal muscular atrophy type I and implications for clinical trials. Neurology. 2014:83(9):810-7.

10. Markowitz JA, Singh P, Darras BT. Spinal muscular atrophy: a clinical and research update. Pediatr Neurol. 2012;46(1):1-12.

11. Lally C, Jones CC, Cook SF, Farwell W, Staropoli J, Flanders WD. Genetic causes of death in US infants: findings from the National Center for health Statisitcs. Presented at: The 67th annual meeting of the American Society of Human Genetics. Orlando; 2017.

12. Finkel R, Chiriboga C, Vasjar J, Day J, Montes J, De Vivo DC, Yamashita M, Rigo F, Hung G, Schneider E et al. Interim results of a phase 2 clinical study of nusinersen (ISIS-SMN $N_{\mathrm{Bx}}$ ) in patients with infantile-onset spinal muscular atrophy.Presented at: 2016 Annual SMA Researcher Meeting: 16-19 June 2016; Anaheim; 2016:53.

13. Spinraza [prescribing Information]. Cambridge: Biogen; 2017. https://www. spinraza.com/content/dam/commercial/specialty/spinraza/caregiver/en_us/ pdf/spinrazaprescribing-information.pdf. Accessed 24 July 2017.

14. Hickman M, Taylor C: Indirect methods to estimate prevalence. Epidemiology of drug abuse. Sloboda Z, ed. Boston: Springer; 2005:113-131.

15. Verhaart IEC, Robertson A, Wilson IJ, Aartsma-Rus A, Cameron S, Jones CC, Cook SF, Lochmuller H. Prevalence, incidence and carrier frequency of 5qlinked spinal muscular atrophy - a literature review. Orphanet J Rare Dis. 2017;12(1):124.

16. Arkblad E, Tulinius M, Kroksmark AK, Henricsson M, Darin N. A populationbased study of genotypic and phenotypic variability in children with spinal muscular atrophy. Acta Paediatr. 2009;98(5):865-72.

17. Tassie B, Isaacs D, Kilham H, Kerridge I. Management of children with spinal muscular atrophy type 1 in Australia. J Paediatr Child Health. 2013;49(10):815-9.

18. Hendrickson BC, Donohoe C, Akmaev VR, Sugarman EA, Labrousse P, Boguslavskiy L, Flynn K, Rohlfs EM, Walker A, Allitto B, et al. Differences in SMN1 allele frequencies among ethnic groups within North America. J Med Genet. 2009;46(9):641-4.

19. Sugarman EA, Nagan N, Zhu H, Akmaev VR, Zhou Z, Rohlfs EM, Flynn K Hendrickson BC, Scholl T, Sirko-Osadsa DA, et al. Pan-ethnic carrier screening and prenatal diagnosis for spinal muscular atrophy: clinical laboratory analysis of >72,400 specimens. Eur J Hum Genet. 2012;20(1):27-32.

20. Oskoui $\mathrm{M}, \mathrm{Ng} \mathrm{P}$, Liben S, Zielinski D. Physician driven variation in the care of children with spinal muscular atrophy type 1. Pediatr Pulmonol. 2017;52(5):662-8.

21. Roper H, Quinlivan R. Implementation of "the consensus statement for the standard of care in spinal muscular atrophy" when applied to infants with severe type 1 SMA in the UK. Arch Dis Child. 2010;95(10):845-9.

22. Benson RC, Hardy KA, Gildengorin G, Hsia D. International survey of physician recommendation for tracheostomy for spinal muscular atrophy type I. Pediatr Pulmonol. 2012;47(6):606-11.

23. Bladen CL, Thompson R, Jackson JM, Garland C, Wegel C, Ambrosini A, Pisano P, Walter MC, Schreiber O, Lusakowska A, et al. Mapping the differences in care for 5,000 spinal muscular atrophy patients, a survey of 24 
national registries in North America, Australasia and Europe. J Neurol. 2014; 261(1):152-63.

24. Ogino S, Wilson RB. Spinal muscular atrophy: molecular genetics and diagnostics. Expert Rev Mol Diagn. 2004;4(1):15-29.

25. Finkel R, Bertini E, Muntoni F, Mercuri E. 209th ENMC international workshop: outcome measures and clinical trial readiness in spinal muscular atrophy 7-9 November 2014, Heemskerk, The Netherlands. Neuromuscul Disord. 2015;25(7):593-602

26. National population projections: United States by age, gender, ethnicity and race for the years 2014-2060. https://wonder.cdc.gov/wonder/help/ PopulationProjections-2060.html. Accessed 14 June 2017.

27. Arias E. United States life tables, 2010. Natl Vital Stat Rep. 2014;63(7):1-63.

28. Jedrzejowska M, Milewski M, Zimowski J, Zagozdzon P, Kostera-Pruszczyk A, Borkowska J, Sielska D, Jurek M, Hausmanowa-Petrusewicz I. Incidence of spinal muscular atrophy in Poland-more frequent than predicted? Neuroepidemiology. 2010;34(3):152-7.

29. Prior TW, Snyder PJ, Rink BD, Pearl DK, Pyatt RE, Mihal DC, Conlan T, Schmalz B, Montgomery L, Ziegler K, et al. Newborn and carrier screening for spinal muscular atrophy. Am J Med Genet A. 2010;152A(7):1608-16.

30. Kaufmann P, McDermott MP, Darras BT, Finkel RS, Sproule DM, Kang PB, Oskoui M, Constantinescu A, Gooch CL, Foley AR, et al. Prospective cohort study of spinal muscular atrophy types 2 and 3. Neurology. 2012;79(18):1889-97.

31. Lemoine TJ, Swoboda KI, Bratton SL, Holubkov R, Mundorff M, Srivastava R. Spinal muscular atrophy type 1: are proactive respiratory interventions associated with longer survival? Pediatr Crit Care Med. 2012;13(3):e161-5.

32. Oskoui M, Levy G, Garland CJ, Gray JM, O'Hagen J, De Vivo DC, Kaufmann P. The changing natural history of spinal muscular atrophy type 1. Neurology. 2007;69(20):1931-6.

33. Mannaa MM, Kalra M, Wong B, Cohen AP, Amin RS. Survival probabilities of patients with childhood spinal muscle atrophy. J Clin Neuromuscul Dis. 2009;10(3):85-9

34. Ge X, Bai J, Lu Y, Qu Y, Song F. The natural history of infant spinal muscular atrophy in China: a study of 237 patients. J Child Neurol. 2012;27(4):471-7.

35. Zerres K, Rudnik-Schöneborn S. Natural history in proximal spinal muscular atrophy. Clinical analysis of 445 patients and suggestions for a modification of existing classifications. Arch Neurol. 1995;52(5):518-23.

36. Chung BH, Wong VC, Ip P. Spinal muscular atrophy: survival pattern and functional status. Pediatrics. 2004;114(5):e548-53.

37. Farrar MA, Vucic S, Johnston HM, du Sart D, Kiernan MC. Pathophysiological insights derived by natural history and motor function of spinal muscular atrophy. J Pediatr. 2013;162(1):155-9.

\section{Submit your next manuscript to BioMed Central and we will help you at every step:}

- We accept pre-submission inquiries

- Our selector tool helps you to find the most relevant journal

- We provide round the clock customer support

- Convenient online submission

- Thorough peer review

- Inclusion in PubMed and all major indexing services

- Maximum visibility for your research

Submit your manuscript at www.biomedcentral.com/submit

) Biomed Central 